\title{
MEDICAL EDUCATION
}

\section{Reflections on Building a Postgraduate Medical Centre*}

\author{
JOHN LISTER, $\dagger$ M.D., F.R.C.P.
}

Brit. med. F., 1966, 1, 228-230

Since the Oxford Conference of $1961 \ddagger$ the pattern of regional postgraduate medical education has gradually been emerging, the local centre becoming the focal point for each area.

Windsor was selected as a site for such a centre. From the geographical and administrative aspects it is the central point in the area served by the Windsor Group H.M.C. (Fig. 1).

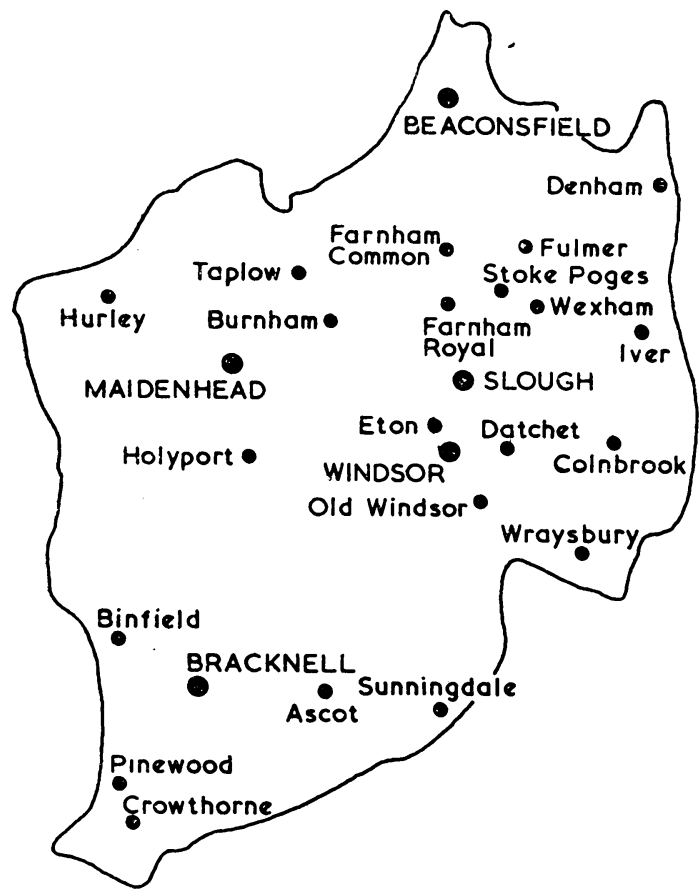

FIG. 1.-Area served by the Windsor and District Postgraduate Medical Centre.

The population is about 350,000 and there are about 170 general practitioners practising in the area, with 75 consultants and 75 junior medical staff working in the five general hospitals in the group. It was hoped that financial support would be forthcoming from the Nuffield Foundation, and plans were made on this assumption until news was received that the sum of $£ 250,000$ set aside for regional postgraduate education had all been allocated. No funds were available from any other official source, since at that time it was not permissible to spend Exchequer funds on regional postgraduate teaching and Windsor was outside the area covered by the King Edward's Fund.

Nevertheless, the local postgraduate committee felt that in order to provide the kind of activities thought necessary a suitable building must be erected with the following minimum requirements: (1) a lecture theatre to seat at least $100 ;(2)$ a library which should be so built that it could also be used

\footnotetext{
* Paper read at the A.S.M.E. Conference in Birmingham, November 1965.

† Consultant Physician and Clinical Tutor to Windsor Group of

:‡ See Brit. med. F., 1962, 1, 466.
}

as an extension of the lecture theatre; (3) a small room which could be used as a seminar room, a committee room, and for social purposes ; (4) office accommodation for the clinical tutor and secretary ; (5) toilet facilities ; (6) a small kitchen.

\section{Cost of the Centre}

The minimum cost of providing a building with this accommodation was estimated at $£ 10,000$, assuming there would be no cost for the land, and it was estimated that a further $£ 5,000$ would be required to see the building adequately equipped. It was also estimated that a sum of approximately $£ 1,500$ to $£ 1,800$ per annum would be required for running expenses, one of the major items being a secretary's salary.

With this end in view a number of leading local industrialists were approached for help in July 1963, and within three months five firms had agreed to become major sponsors of the project and guaranteed a capital sum of $£ 2,000$ each, together with the promise of an annual contribution towards running costs.

This generous support enabled plans to be prepared (Figs. 2 and 3 ) and sent out to tender without awaiting the result of a local appeal. A trust deed was drawn up and eventually approved by the Ministry of Education as an educational trust and was submitted to the Charity Commissioners for recognition as a charitable body. The managing directors of the five sponsoring firms became the first trustees, and they invited the Postgraduate Medical Federation to nominate a further trustee in order to ensure a link with the University.

A local appeal realized $£ 6,700$. Support came from many directions. In addition to the help from the major sponsors, contributions were received from other firms in the district, from three local authorities, and from a number of individual subscribers.

Apart from money, there were several gifts in kind, including a film projector, recording apparatus, a well-equipped bar, and all the paint required for the building.

The local medical profession also contributed generously: 120 general practitioners and consultants made individual contributions, and the consultant staff of King Edward VII Hospital contributed from the fund which had been accumulated as the result of running refresher courses for general practitioners. The Windsor and District Medical Society also gave its support and was represented on the Postgraduate Committee.

The financial position was further strengthened when the Windsor Group Hospital Management Committee joined the five industrial firms in also guaranteeing $£ 2,000$ from its meagre "free moneys" and by the North-west Regional Hospital Board making a grant of $£ 2,000$ towards the cost of equipment when Treasury regulations were relaxed in 1964 and permitted the expenditure of their Exchequer funds to assist such projects. This relaxation also brought with it the hope that running costs would be met from Exchequer funds and prompted the major sponsors to change their initial offer 
of guaranteeing $£ 2,000$ to making outright gifts of $£ 2,000$, provided they were not called upon to make annual contributions to running costs.

As a result of this combined effort it has been possible to erect a pleasant and functional building at a reasonable cost on land at Windsor Hospital leased to the Trustees at a peppercorn rent of $£ 1$ per annum.

Furthermore, though the cost of the building and of site improvement was slightly in excess of the original estimate, the cost of equipment was less than anticipated, chiefly because of the generous gifts already mentioned (see Tables I and II).

\section{Difficulties}

Attitude of Doctors.-It was thought to be essential that the doctors should demonstrate that they wanted a centre by themselves contributing towards the cost. Contributions of five guineas were invited. Some responded immediately, others after a second or third approach, while others were clearly conscientious objectors, believing that the State or, at any rate, someone else should provide the centre.

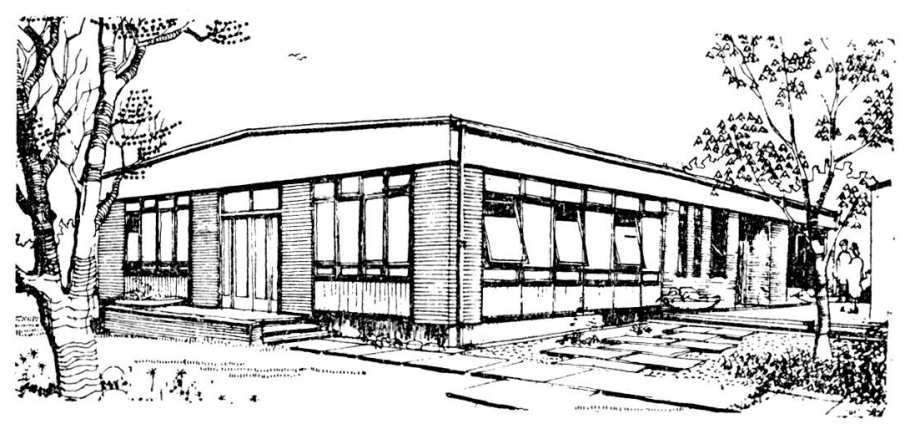

FIG. 2.-Sketch of the Postgraduate Medical Centre.

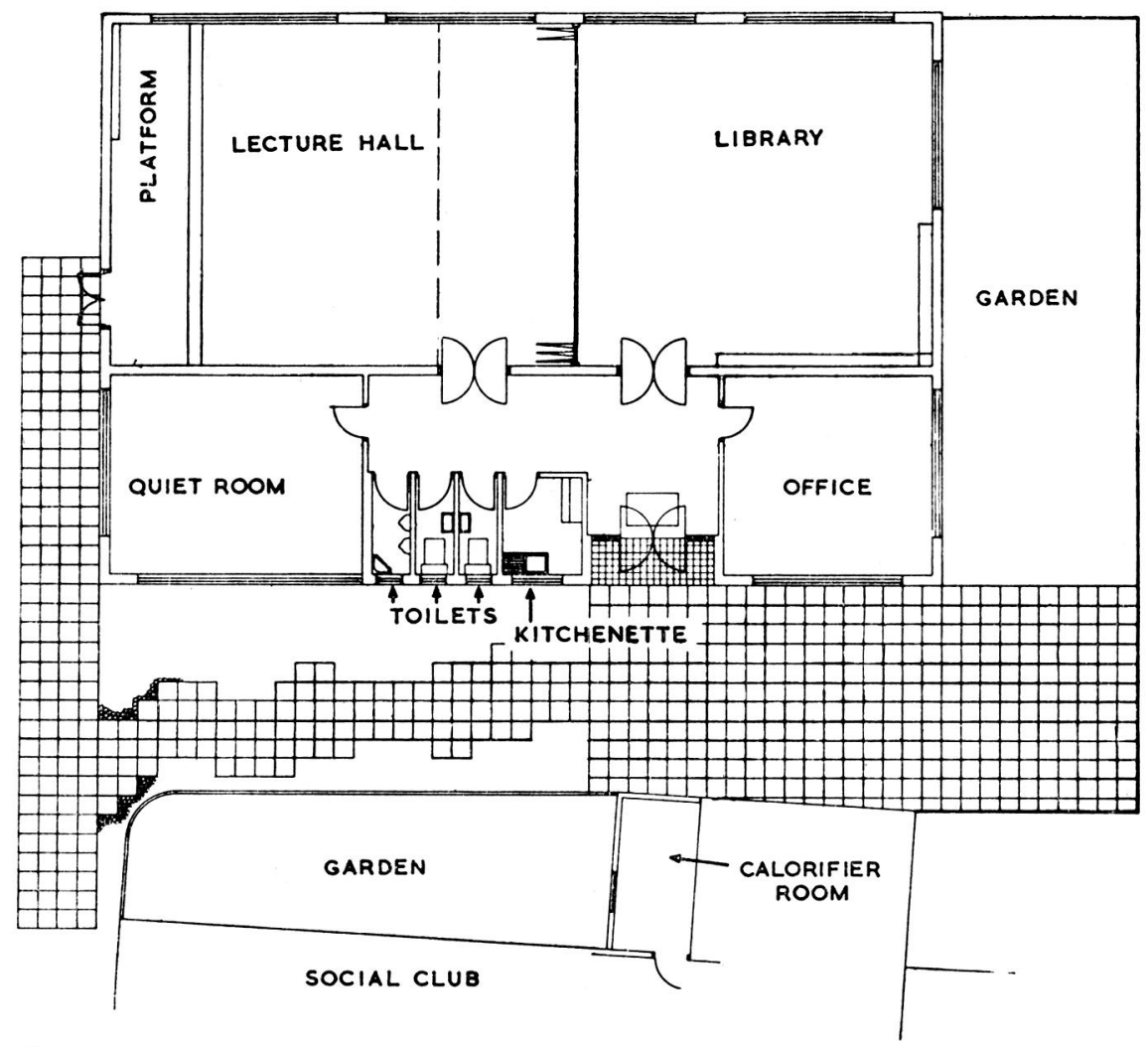

FIG. 3.-Architects' plan of the centre. The building has a total area of 2,870 sq. $\mathrm{ft}$. (267 sq. m.).
TABLB I.-Estimated Receipts and Expenditure Receipts

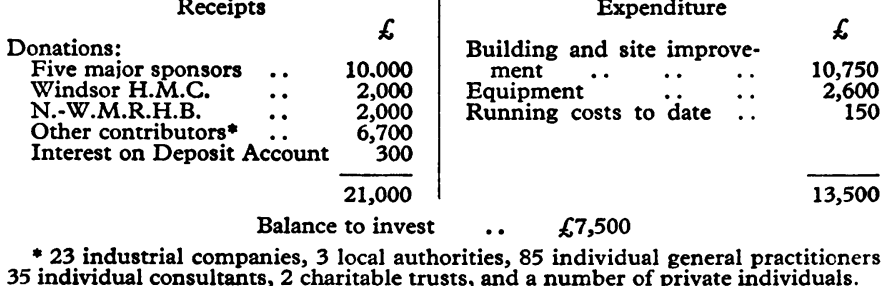

TABLB II.-Cost of Equipment

Equipment

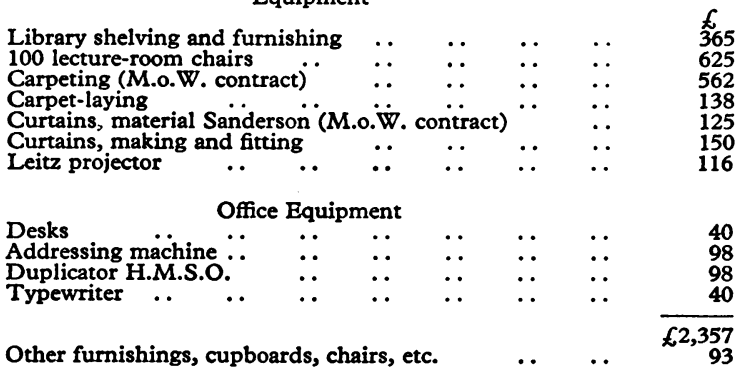

Gas cooker, clocks, etc. $\begin{array}{lllllll}\text { Other Items } & . & \ldots & \ldots & \ldots & \ldots & \frac{150}{£ 2,600}\end{array}$

Local Medical Society.-A proposal was made that the subscription be increased by half a guinea so that an annual sum of $£ 100$ could be paid to the Trustees. The majority of members readily agreed, but a small minority again resisted the proposal on the ground that the centre should be provided by the State. Nevertheless, the proposal was finally accepted.

General Appeal.-About 2,000 letters of appeal were sent out, but only a minute proportion of the recipients made contributions. This chiefly reflects the necessity for the personal approach, but a number of letters were received which again stated that this kind of activity should not require public support. A few local authorities also objected on the same grounds, the following letter being received from one authority:

"I was under the impression that no public appeals were to be made, but that the money was to be sought from certain selected private bodies and individuals only.

"As I have been asked by the Mayor to present the case for such a contribution to the Committee, I shall be very pleased if you will let me know the way in which you think this matter should be dealt with bearing in mind particularly the fact that one profession, or part of it, is asking for a contribution from the public's funds which will only benefit them indirectly."

Regional Hospital Board.-The Board naturally applauded the efforts at local level, but initially were unable to give any financial help. And when they were permitted to do so they discovered that there were difficulties in the way of the Board contributing to a private trust, and wrote: "The Buard is likely to make a contribution. if the technical difficulties of contributing to an independent body can be overcome." It was arranged, however, that their $£ 2,000$ was to be spent in such a way that the Government auditors could not object, since it was never handled by any private individual, but equipment to the value of $£ 2,000$ was purchased from Exchequer funds. 
Hospital Management Committee.-The Hospital Management Committee also applauded local initiative and gave support from free moneys, but are having difficulty in finding funds to meet running costs, since the Board now claim that the Trustees in their original commitments agreed to run the centre for seven years. This was in spite of the fact that the Trustees had changed their offer from guaranteeing $£ 2,000$ each to making outright gifts of $£ 2,000$ each on the understanding that the new conditions brought about by the Treasury relaxation would provide for maintenance of the centre from Exchequer funds. By patient negotiation, however, a satisfactory compromise was eventually reached, and the centre seems assured that funds will be forthcoming from several sources (see Table III).

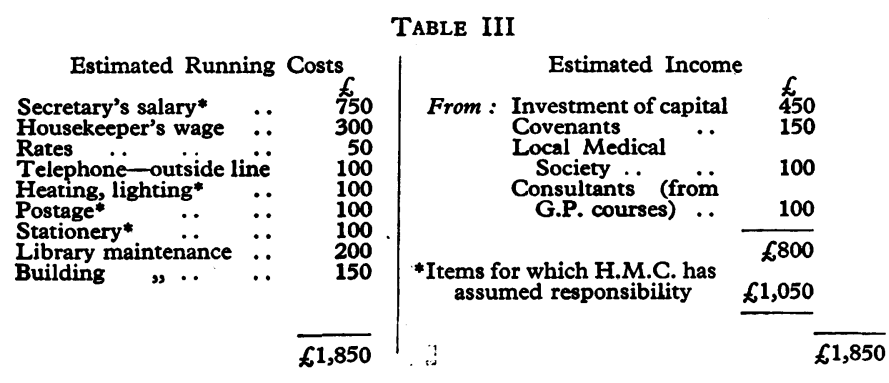

\section{Discussion}

There can be no doubt that the provision of medical centres in management committee areas will become a major factor in counteracting the tendency to fragment the medical profession that has been such a marked defect of the organization of the N.H.S.

The successful completion of the building at Windsor within two years of the approach to local industry has been partly due to a deliberate policy of not being too ambitious and concentrating on providing minimum requirements. These will differ for each area, but it is essential that they should be defined early in the planning stage, and it is wise to avoid being too ambitious.
Each area will also have different sources of financial support, but the principle of co-operation between the local medical profession and local industry on the one hand and the Hospital Management Committee and the Regional Board on the other has already proved to be rewarding at Windsor.

Anyone assuming the responsibility of planning a centre will learn a good deal about human nature, will discover the need for the protection of a thick skin, and must be prepared never to take "no" for an answer. At the same time he will have the satisfying experience of finding how much latent good will and old-fashioned philanthropy still exists, and, when all the difficulties have been overcome, will earn the gratitude of even his most sceptical colleagues.

\section{Summary}

The Windsor and District Postgraduate Medical Centre has been built as the result of a co-operative effort between the local medical profession, local industry, and the Windsor Hospital Management Committee and the North-west Metropolitan Regional Hospital Board.

It is to be hoped that similar centres will be built in all management committee areas. Each area will have different requirements and different resources. It is emphasized that these should be assessed early in the planning stage of any centre and that it is wise to avoid being too ambitious and to concentrate on providing the minimum essential requirements.

Much credit must go to Mr. H. Cook, building supervisor to the Windsor Group Hospital Management Committee, who drew up the plans, and to the builders, Messrs. Tyson Chambers, of Slough. Thanks are also due to Dr. L. F. Wiggins, Research Director of Aspro-Nicholas, secretary to the Trustees, and to Mr. H. Lamb, Group Secretary, both of whom gave much time and showed such interest in planning the project.

Finally, the centre could not have been erected so quickly without the prompt assistance of the five major sponsoring firms-AsproNicholas, Crookes Laboratories, High Duty Alloys, Miles Laboratories, and Slough Estates.

\section{Formation of the Migraine Trust}

At a dinner given to a group of industrialists at the Apothecaries Hall on 18 January LORD BRAIN announced the formation of the Migraine Trust, of which he is chairman, and appealed for $£ 750,000$ over the next 10 years. The other trustees are LORD and Lady Snow, Sir Cyril Musgrave, and Dr. MACDONALD CRITCHLEY ; the honorary treasurer is LORD ALDINGTON.

LORD BRAIN told his audience that a group of medical experts had been investigating the possibility of research into the problem of migraine, and had concluded that there were good prospects for progress in knowledge and treatment if the research were approached on a planned methodical basis. The Migraine Trust had been formed to organize and finance this work, and an office would be opened to co-ordinate research. A scientific journal was planned, in which original papers and abstracts of world literature would be published. It was also proposed to establish research fellowships.

The revolutionary developments in the application of electronics, radio-isotopes, and other advances in medicine had opened new doors to the study of the brain. This had made possible progress in research into the scourge of migraine headaches.

An early start could be made with a pro- ject at the National Hospital, London, which had the largest migraine and headache clinic in the National Health Service. Other research was envisaged, possibly in Birmingham, Glasgow, and elsewhere.

Before the research began, the Trust had to be sure that it could finance the work for about 10 years. This would require a minimum of $£ 75,000$ a year. Lord Brain asked for immediate help in raising this money, and announced that in a few months' time a campaign would be launched to appeal for funds. A gift of $£ 2,000$ had been received from the British Migraine Association, an organization of sufferers from migraine. 